\title{
IMPLEMENTASI CONTEXT AWARE PADA SISTEM TRAVEL PLANNER BERBASIS MOBILE
}

\author{
Viery Darmawan ${ }^{\bowtie}$, Rengga Asmara, Ira Prasetyaningrum \\ Program Studi D4 Teknik Informatika, Politeknik Elektronika Negeri Surabaya, Indonesia \\ Email: vierydarmawan2@gmail.com
}

DOI: $\underline{\text { https://doi.org/10.46880/jmika.Vol5No1.pp23-27 }}$

\begin{abstract}
In the era of technological advances, tourists will first seek information about the tourist object to be addressed, even tourists often don't have a destination, so they have to search one by one via the internet. In determining travel plans, it is often to see one by one the review of tourist attractions and conclude the results will take a long time, while tourists need actual and fast information to determine the travel plans. In this study, the authors take a new approach, namely by creating a mobile-based travel planner system that compiles travel plans automatically by considering contextual information related to tourist location points, whether of tourist locations during travel days, travel opening and closing hours, so that it will increase travel efficiency without having to do the research manually which takes a long time. The system can also provide travel recommendations based on visitor comments sentiment on Google Places and is equipped with a trip route that will be generated automatically. This research is useful for helping tourists plan their trip actually because of the consideration of contextual information so that it will make it easier and save tourists time.
\end{abstract}

Keyword: Travel Planner, Context-Aware, Recommendation System.

\section{ABSTRAK}

Di era kemajuan teknologi, wisatawan akan lebih dahulu mencari informasi mengenai objek wisata yang akan dituju, bahkan seringkali wisatawan belum memiliki destinasi, sehingga harus mencari satu per satu via internet. Dalam menentukan rencana perjalaan seringkali untuk melihat satu persatu review objek wisata dan menyimpulkan hasilnya akan membutuhkan waktu yang lama, sedangkan wisatawan membutuhkan informasi yang aktual serta cepat untuk menentukan rencana perjalanan. Pada penelitian ini penulis melakukan pendekatan baru, yakni dengan membuat sistem travel planner berbasis mobile yang menyusun rencana perjalanan secara otomatis dengan mempertimbangkan informasi kontekstual terkait titik lokasi wisata, cuaca lokasi wisata saat hari berpergian, jam buka-tutup wisata, sehingga akan meningkatkan efisiensi perjalanan tanpa harus melakukan riset secara manual yang membutuhkan waktu lama. Sistem juga dapat memberikan rekomendasi wisata berdasarkan sentimen komentar pengunjung pada Google Places dan dilengkapi dengan rute perjalanan yang akan generate secara otomatis. Penelitian ini bermanfaat untuk membantu wisatawan dalam merencanakan perjalannya secara aktual karena adanya pertimbangan infomasi kontekstual sehingga akan mempermudahkan dan menghemat waktu wisatawan.

\section{Kata Kunci: Travel Planner, Context-Aware, Sistem Rekomendasi.}

\section{PENDAHULUAN}

Dalam dunia pariwisata, media mempunyai peranan krusial dalam pertumbuhan dan kemajuan pariwisata, salah satunya dengan menyampaikan informasi secara mendalam tentang objek-objek wisata yang dibutuhkan oleh wisatawan domestik maupun mancanegara melalui internet. Di era kemajuan teknologi, ada perubahan perilaku para wisatawan dimana wisatawan akan lebih dahulu mencari informasi atau riset mengenai objek wisata yang akan dituju, bahkan seringkali wisatawan belum memiliki destinasi, sehingga harus mencari satu per satu via internet. Selain riset, agar memudahkan serta memperlancar saat berwisata, wisatawan akan membuat penyusunan itinerary (rencana perjalanan). Itinerary dibuat untuk memudahkan mengetahui jadwal-urutan- langkah yang harus dijalani dalam melakukan perjalanan.

Pembuatanitinerary dengan mempertimbangkan beberapa hal secara manual akan menghabiskan banyak waktu, terlebih saat wisatawan belum pernah mengunjungi lokasi- lokasi tersebut sehingga tak jarang wisatawan akan melakukannya dengan sesederhana mungkin dan tidak detil dalam perencanaannya. Pencarian informasi mengenai objek wisata pun dilakukan secara manual dengan memanfaatkan search engine, media sosial, informasi rekomendasi dari kerabat 
maupun melihat review dari layanan populer seperti TripAdvisor ataupun Goolgle Places. Namun untuk melihat satu persatu review objek wisata dan menyimpulkan hasilnya akan membutuhkan waktu yang lama (Asmara, Prasetyaningrum, \& Rahmawati, 2019). Sedangkan wisatawan membutuhkan informasi yang aktualserta cepat untuk menentukan rencana perjalanan.

Berangkat dari permasalahan yang ada, penulis mencoba untuk melakukan pendekatan baru, yakni dengan membuat sistem travel planner yang menyusun rencana perjalanan (itinerary) secara otomatis dengan mempertimbangkan informasi kontekstual (context aware) terkait titik lokasi wisata, cuaca lokasi wisata saat hari berpergian, jam buka-tutup wisata, sehingga akan meningkatkan efisiensi perjalanan. Sistem juga dapat memberikan rekomendasi wisata berdasarkan komen pada GooglePlaces dan dilengkapi dengan rute perjalanan yang akan generate secara otomatis (Yoon, Zheng, Xie, \& Woo, 2010).

\section{TINJAUAN PUSTAKA}

\section{Sistem Travel Planner}

Aplikasi Travel Planner berguna untuk memudahkan para calon wisatawan dalam merencanakan perjalanan, dengan memberikan rekomendasi yang telah mempertimbangkan informasi kontekstual berupa nilai sentimen dari review, jarak, jam operasional serta cuaca sehingga pengguna akan mendapatkan hasil rekomendasi yang lebih aktual. Sistem akan mengelola informasi kontekstual tersebut untuk menentukan rencana perjalanan (Zhengchuan, Yu, Jun, \& Tingjie, 2013).

\section{Context Aware}

Context sendiri adalah informasi yang digunakan menggam-barkan atau mengklasifikasi lingkungan suatu entitas. Salah satu pen-erapan context-aware adalah geofence. Geofence adalah sebuah pembatas virtual dalam hal pergerakan objek pada suatu area, sehingga ketika objek melewati pembatas akan diberikan suatu aware kepada pemantau (Agustian, Trisnadoli, \& Lestari, 2018). Informasi kontekstual adalah hal yang sangat vital dalam perolehan rekomendasi yang relevan. Hal tersebut menjadikan context-aware merupakan salah satu pendekatan yang efektif dalam memahami kebutuhan pengguna (Rizaldy Hafid Arigi, Abdurahman Baizal, \& Herdiani, 2018).

\section{OpenWeatherMap}

OpenWeatherMap adalah layanan online yang menyediakan data cuaca termasuk cuaca saat ini, perkiraan, dan riwayat cuaca untuk para devel-operweb services dan mobile application (Wikipedia Contributor, 2020).

\section{Text Mining}

Text mining memiliki definisi menambang data yang berupa teks dimana sumber data biasanya di dapatkan dari dokumen dan tujuannya adalah mencari kata-kata yang dapat mewakili isi dari dokumen sehingga dapat dilakukan analisa keterhubungan antar dokumen (Siringoringo \& Jamaluddin, 2019).

\section{Sistem Rekomendasi}

Sistem rekomendasi adalah fitur-fitur dan teknikteknik pada perangkat lunak yang menyediakan sesuatu hal yang berguna untuk user. Sistem rekomendasi juga menyediakan rekomendasi-rekomendasi dari beberapa item yang berpotensi menarik untuk pengguna. Rekomendasi rekomendasi yang diberikan erat kaitannya dengan pengambilan keputusan, seperti item apa saja yang harus dibeli, musik seperti apa yang harus didengarkan, dan berita apa yang harus dibaca. Dalam hal ini, item adalah sebuah objekyang direkomendasikan (Firmahsyah \& Gantini, 2016).

\section{METODE PENELITIAN}

Untuk merancang dan membuat penelitian ini, ada beberapa tahap yang dilakukan yaitu:

\section{Studi Literatur}

Studi literatur merupakan langkah awal dalam pengerjaan proyek akhir ini. Tahapan ini merupakan tahap penting untuk mempelajari teori-teori serta konsep teknis maupun non-teknis yang menunjang dalam pengerjaan penelitian ini.

\section{Pengumpulan Data}

Tahap ini akan dilakukan pengumpulan data yang diperlukan untuk mendukung pengerjaan proyek akhir. Data yang diperlukan oleh peneliti adalah data terkait objek wisata yang didapatkan dari GooglePlaces.

\section{Perancangan Sistem}

Setelah melakukan studi literatur dan pengumpulan data, maka tahap selanjutnya adalah perancangan pembuatan sistem rekomendasi rencana perjalanan yang mengimplementasikan context aware, dengan tujuan untuk merekomendasikan rencana perjalanan paling optimal, sehingga estimasi waktu yang dihabiskan lebih efisien.

\section{Implementasi Sistem}

Pada tahap ini, penulis mengimplementasikan 
sistem yang telah dirancang pada tahap perancangan sistem untuk selanjutnya.

\section{Pengujian dan Analisis}

Pada tahap ini, penulis melakukan pengujian terhadap sistem yang telah diimplementasikan pada tahap implementasi sistem. Pengujian dilakukan dengan pengujian biaya, ruang, waktu agar dihasilkan sistem yang dapat diakses tanpa batasan biaya, dimanapun dan kapanpun.

\section{HASIL DAN PEMBAHASAN}

\section{Pengujian Fungsionalitas Sistem}

Destinasi Otomatis merupakan fitur utama dari penelitian ini dimana sistem akan mendapatkan rekomendasi rencana perjalanan dengan mempertimbangkan lokasi, perkiraan cuaca, status buka tutup, jarak terdekat hingga rute yang harus dilalui. Dimana user cukup menginputkan kategori wisata yang diinginkan, tanggal berwisata, dan lokasi awalnya, sistem akan dengan otomatis memberikan rekomendasi lengkap dengan tempat wisata yang akan dituju.
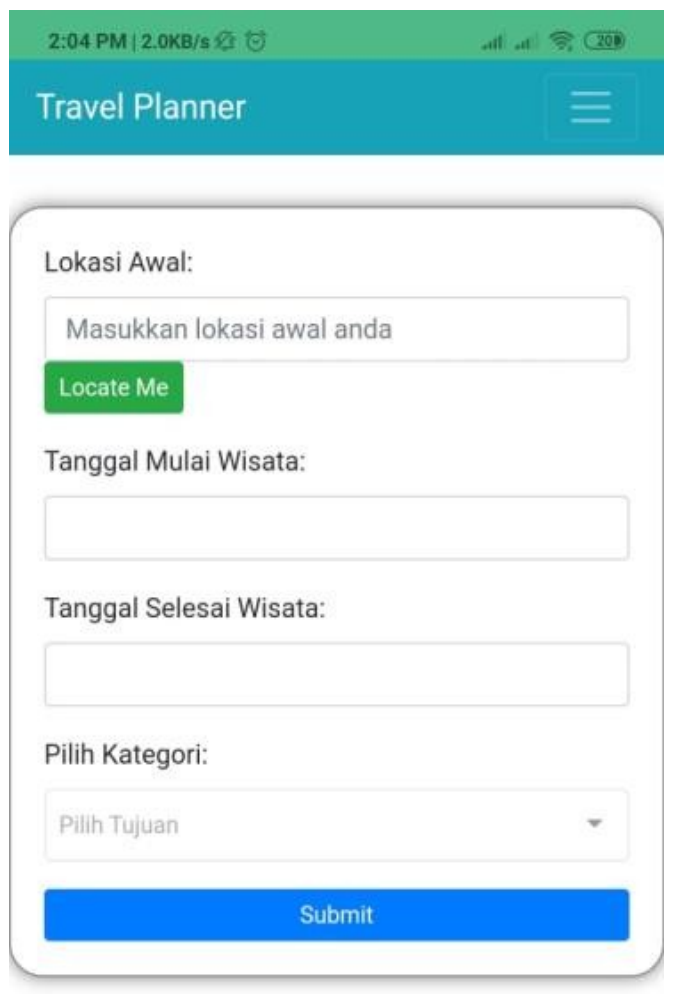

Gambar 1. Halaman Utama

\section{Input Lokasi Awal}

Input lokasi awal diperlukan untuk mengetahui dimana titik lokasi awal pengguna dalam berwisata, seperti misalnya hotel atau tempat tertentu, sesuai pada gambar 2 .

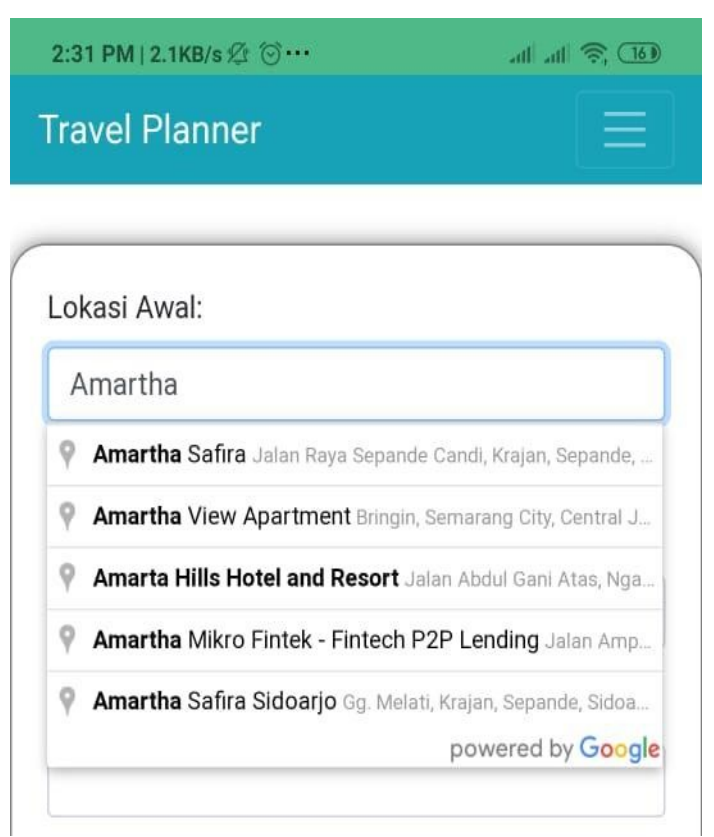

Gambar 2. Input Lokasi Awal

\section{Input Tanggal Berwisata}

Informasi tanggal berguna untuk mengetahui kapan dan berapa lama pengguna akan berwisata, serta untuk mempertimbangkan cuaca, status buka yang membutuhkan informasi tanggal. Contoh dari inputan tanggal ada pada gambar 3 .

\section{Tanggal Mulai Wisata:}

\section{$07 / 09 / 2020$}

Tanggal Selesai Wisata:

$07 / 10 / 2020$

Gambar 3. Input Tanggal Wisata

\section{Input Kategori}

Gambar 4 adalah contoh user saat input kategori yang bertujuan untuk mengetahui jenis wisata apa yang diinginkan oleh pengguna, karna pada fitur ini user tidak menginputkan tempat wisata, sistem akan memberikan rekomendasi wisata yang sesuai dengan kategori wisata yang diinginkan pengguna 


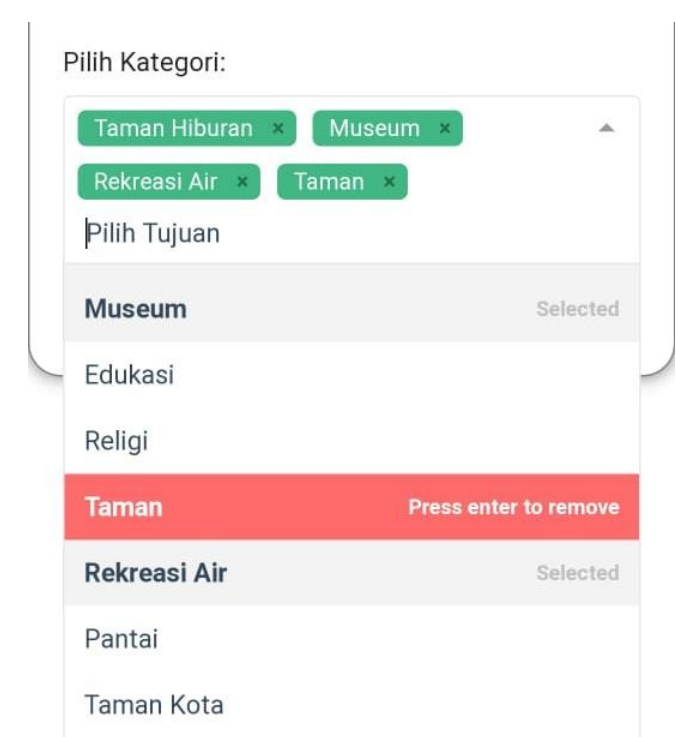

\section{Gambar 4. Input Kategori}

\section{Output Tabel Rencana Perjalanan}

Setelah mengisikan semua informasi yang diperlukan, system akan memberikan tabel rencana perjalanan

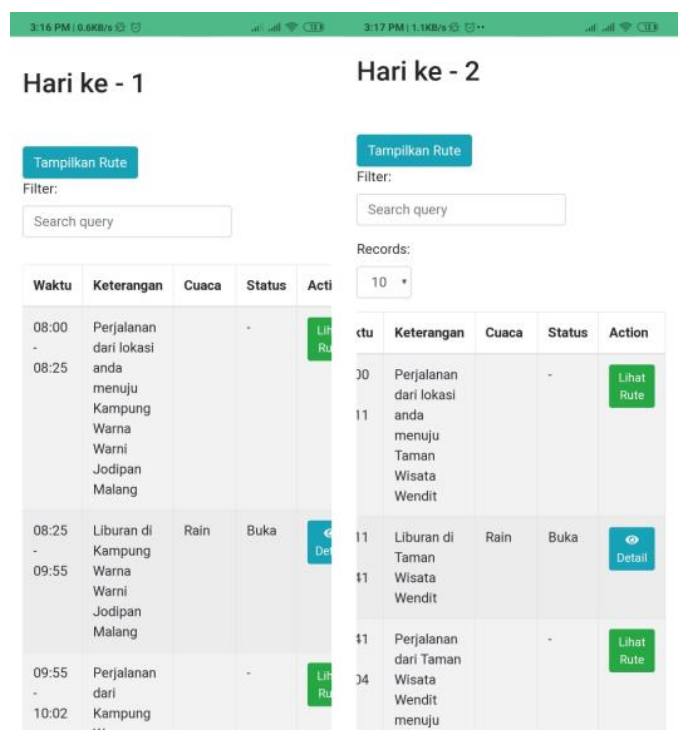

Gambar 5. Output Rencana Perjalanan

Gambar 5 menunjukan hasil rekomendasi rencana perjalanan oleh sistem, yang terdiri waktu, keterangan, cuaca, status buka. Dimana system telah memberikan rekomendasi yang telah mempertimbang-kan informasi kontekstual berupa jarak terdekat, jambuka, serta informasi cuaca.

\section{Peta Rencana Perjalanan}

Sitem juga menyediakan peta perjalanan yang akan dilalui pengguna untuk masing masing harinya. Pada output rencana perjalanan, diatas table tersedia tombol untuk menampilkan peta perjalanan pengguna.

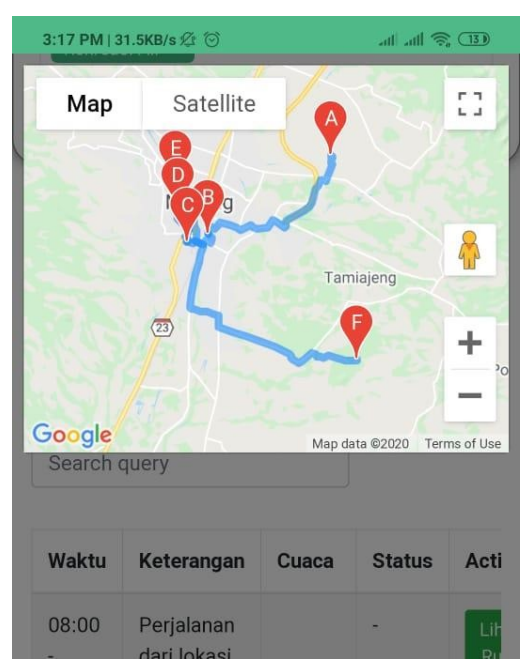

Gambar 6. Peta Rencana Perjalanan

Pada gambar 6 menunjukkan peta perjalanan pengguna dimulai dari lokasi awal pengguna yang disimbolkan dengan alphabet A sampai dengan destinasi terakhir.

\section{Detail Informasi Destinasi}

Pada tabel rencana perjalanan kolom action terdapat tombol Detail yang bertujuan untuk menampilkan informasi lebih lengkap mengenai destinasi yang akan dituju.

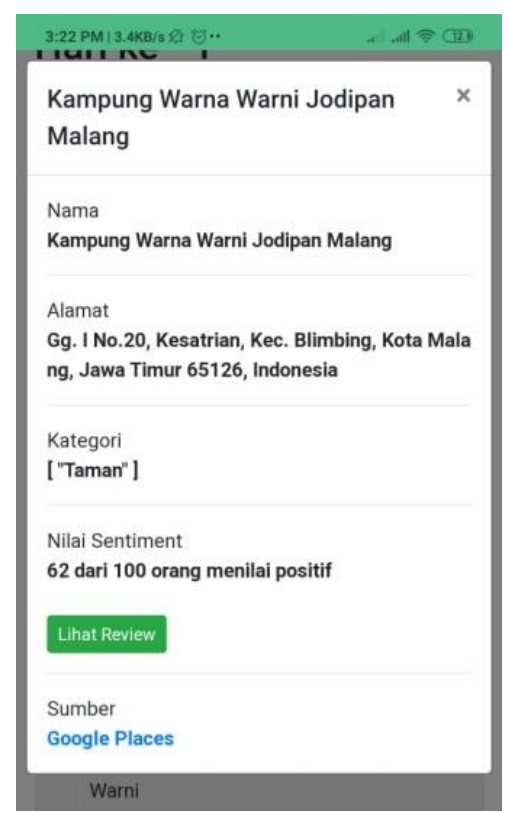

Gambar 7. Informasi Detail Destinasi 


\section{Informasi Review Destinasi}

Pada informasi detail destinasi bagian nilai sentiment terdapat tombol Lihat Review untuk menunjukan sentiment review terhadap destinasi terkait yang bersumber pada google places.

\section{Kampung Warna \\ Warni Jodipan Malang}

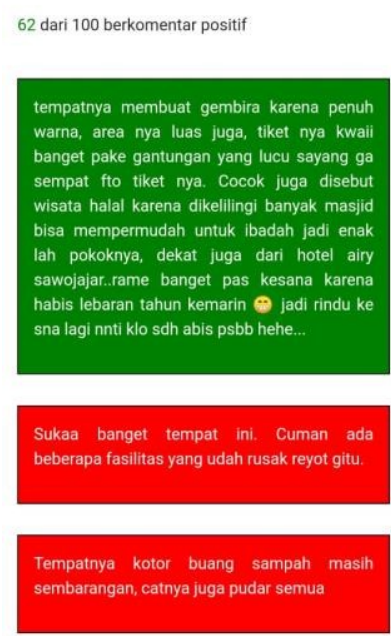

Gambar 8. Informasi Sentimen Destinasi

Gambar 8 menunjukan informasi review dari wisata Kampung Warna Warni Jodipan, infromasi yang diberikan berupa jumlah review positif dari total review. Serta menunjukan masing masing review yang telah diberikan indicator warna hijau untuk review positif, merah untuk review negative, dan putih untuk review netral.

\section{KESIMPULAN}

Sistem Travel Planner yang berguna untuk membatu para calon wisaatawan untuk memberikan rekomendasi rencana perjalanan akan sangat lebih efektif jika mempertimbangkan informasi kontekstual berupa jam operasional tempat wisata, jarak terdekat, cuaca sekitar dan nilai sentiment pada review yang akan membantu memberikan rekomendasi tempat wisata yang memiliki nilai sentimenttertinggi.

Penulis telah mengimplementasikan context aware pada sistem untuk merekomendasikan rencana perjalanan kepada pengguna, untuk jam operasional, sistem akan menghindari jam operasional tepat wisata yang masih tutup dan mengutamakan yang sudah beroperasi pada jam dimana calon wisatawan akan berkunjung, untuk niali sentiment dari review digunakan untuk mendapatkan 10 tempat wisata untuk masing hari yang sesusi dengan kategori yang diinginkan pengguna dan jaraknya tidak lebih dari $30 \mathrm{KM}$. Untuk prakiraan cuaca tidak dijadikan acuan pasti dalam merekomendasikan destinasi karena cuaca masih berupa prakiraan dan belum dipastikan kebenarannya, karena itu cuaca hanya dijadikan suatu informasi kepada pengguna.

\section{DAFTAR PUSTAKA}

Agustian, A., Trisnadoli, A., \& Lestari, I. (2018). Analisis Hasil Implementasi Konsep ContextAware Pada Aplikasi Mobile Family Tracking Untuk Platform Android. Teknika, 7(1), 34-41. https://doi.org/10.34148/teknika.v7i1.84

Asmara, R., Prasetyaningrum, I., \& Rahmawati, S. Z. (2019). Penyusunan Itinerary Otomatis Tempat Wisata Jatim Menggunakan Google Maps Dan Multitransportasi. INOVTEK Polbeng - Seri Informatika, 4(2), 179. https://doi.org/10.35314/isi.v4i2.1099

Firmahsyah, F., \& Gantini, T. (2016). Penerapan Metode Content-Based Filtering Pada Sistem Rekomendasi Kegiatan Ekstrakulikuler (Studi Kasus di Sekolah ABC). Jurnal Teknik Informatika Dan Sistem Informasi, 2(3), 414427. https://doi.org/10.28932/jutisi.v2i3.548

Rizaldy Hafid Arigi, L., Abdurahman Baizal, Z. K., \& Herdiani, A. (2018). Context-aware recommender system based on ontology for recommending tourist destinations at Bandung. Journal of Physics: Conference Series, 971, 012024. https://doi.org/10.1088/17426596/971/1/012024

Siringoringo, R., \& Jamaluddin, J. (2019). Text Mining dan Klasterisasi Sentimen Pada Ulasan Produk Toko Online. Jurnal Teknologi Dan Ilmu Komputer Prima (JUTIKOMP), 2(1), 4148.

Wikipedia Contributor. (2020). OpenWeatherMap. Retrieved from https://en.wikipedia.org/

Yoon, H., Zheng, Y., Xie, X., \& Woo, W. (2010). Smart Itinerary Recommendation Based on User-Generated GPS Trajectories. https://doi.org/10.1007/978-3-642-16355-5 5

Zhengchuan, X., Yu, P., Jun, L., \& Tingjie, L. (2013). Context-aware tour planning system based on satisfaction model. China Communications, 10(6), 156-163. https://doi.org/10.1109/CC.2013.6549267 